\title{
Diagnosis and Treatment of Normal Eating
}

\author{
Janet Polivy and C. Peter Herman \\ University of Toronto \\ Mississauga, Ontario, Canada
}

\begin{abstract}
The shift in societal preference toward a thin physique has led to an increasing prevalence of dieting such that "normal" eating for North American women is now characterized by dieting. In this article, we explore similarities between such normal dieters and individuals with an eating disorder and question whether a continuity exists between normal and abnormal eating behavior. The regulation of intake among normal dieter and patient populations is compared and is explained by the boundary model of consumption, which leads to the conclusion that in neither group is eating technically disordered, although it does depart from appropriate physiological norms. We conclude that many normal eaters (i.e., dieters or restrained eaters) display characteristics of eating-disorder pathologies and should be treated accordingly. Such treatment involves changing both the patient and the environment, especially societal attitudes toward body weight and shape.
\end{abstract}

The current societal preference for a thin physique has spawned a corresponding societal preoccupation with dieting and weight loss. The extent of this preoccupation is such that it may now be accurate to regard dieting and its attendant diet mentality as normative, both descriptively and prescriptively. In short, it is now "normal" for individuals in our society to express concern about their weight and to engage in fitful attempts to change it. A normal lifestyle now requires periodic exercise; normal eating now requires periodic dieting.

Why is a thin physique prized, especially among women? Answers to this question typically refer to historical variation in the sort of physique that is most highly valued. In former times, endomorphy was preferred, as is evidenced by the inevitably referenced Rubenesque nude. Nowadays, women are induced to strive toward a condition of ruddy-cheeked emaciation. Describing this historical shift does not account for it, of course, and the explanations usually tendered are both easy to produce and difficult to prove. Their validity aside, these explanations tend to fall into three classes: The first class focuses on the aesthetics of physique, with thin women seen as more beautiful and, consequently, of greater sexual allure; the second class emphasizes the implicit personality correlates of various physiques, with thinness connoting power, health, and other contemporary values; and the third class infers behaviors from the physique itself, with thinness reflecting the sort of self-control that is presumably required to achieve and maintain slenderness.

Whatever its true cause, the recent shift in societal preference toward a thin physique has been well-documented (DeJong \& Kleck, 1986; Garner \& Garfinkel, 1980; Garner, Garfinkel, \& Olmsted, 1983; Polivy, Garner, \& Garfinkel, 1981, 1986; Polivy

Preparation of this article was assisted by grants from the Natural Sciences and Engineering Research Council of Canada.

Correspondence concerning this article should be addressed to Janet Polivy, Department of Psychology, University of Toronto, Erindale Campus, Mississauga, Ontario, Canada L5L 1 C6.
\& Herman, 1983; Rodin, Silberstein, \& Streigel-Moore, 1985; Silverstein, 1986; Silverstein, Perdue, Peterson, Vogel, \& Fantini, 1986; Wooley \& Wooley, 1982). Corresponding to this shift in body image ideal is a shift in notions of the ideal eating pattern presumed to be responsible for the physique. Societally prescribed eating sanctions the ingestion of sufficient energy and nutrients to maintain health and a thin (or normal) physique but does not sanction ingestion that will lead one to gain weight, to become "overweight," or to attain a fat physique. Prescriptively normal eating in current Western society thus demands that one eat enough to maintain an acceptable body size and no more.

Terms such as normal, acceptable, and overweight can be understood only in the context of societal realities and ideals. Normal, for instance, is more often used in the prescriptive/evaluative sense than in the descriptive/statistical sense. Thus, women whose weight is actually close to the population mean for their age and height may be seen as (and may feel) overweight. By the same token, the meaning of a phrase such as normal eating is no longer obvious. In this article, we shall attempt to distinguish between normal and abnormal eating patterns. We shall argue that societally normal eating may not be normal or appropriate by physiological standards, displays many features of societally acknowledged eating disorders, and may itself be regarded as disordered or pathological. Hence, from this hypothesis springs our paradoxical reference, expressed in the title of this paper, to the diagnosis and treatment of normal eating.

The Diagnostic and Statistical Manual of Mental Disorders (DSM-III; American Psychiatric Association [APA], 1980) identifies five eating disorders-anorexia nervosa, bulimia (or bulimia nervosa), pica, rumination disorder of infancy, and atypical eating disorder - in addition to the physical disorder of simple obesity. (See the DSM-III-R [APA, 1987] for the most recent definitions.) Anorexia nervosa, bulimia, atypical eating disorders (anorexic- or bulimic-like cases that do not quite meet standard diagnostic criteria), and obesity are the most common and are usually referred to when eating disorders are discussed. We shall abide by this convention, using the term eating disor- 
ders to refer only to these four conditions (although we agree with the DSM-III that obcsity is not an eating disorder). ${ }^{1}$

\section{Normal Eating}

Society's current preference for slimness has affected eating behavior and attitudes toward food. As this preference has evolved and has become more strongly entrenched, the media has propagated information on how to achieve a slim physique, mainly by means of weight-reducing diets. Between 1960 and 1980 , the number of diet articles in women's magazines increased dramatically (Garner, Garfinkel, Schwartz, \& Thompson, 1980). Similarly, during this period the number of young women concerned about their body weight who attempted to reduce it through dieting rose dramatically (e.g., see Polivy \& Herman, 1983, for a review). By 1977, three quarters of all female college students surveyed had dieted in an attempt to control their weight (Jacobovits, Halstead, Kelley, Roe, \& Young, 1977). In fact, among young women and adolescent girls, dieting was more prevalent than not dieting and was thus normative (or normal) behavior (Polivy, Garner, \& Garfinkel, 1986; Polivy \& Herman, 1983; Rodin et al., 1985).

What are the implications of dieting as a norm? Do dieters behave differently than nondieters? The evidence indicates that they do: Under a variety of conditions, dieters react to factors affecting eating behavior in a manner virtually opposite to that of nondieters. For example, dieters' reactions to caloric manipulations seem to be almost exclusively under cognitive (rather than physiological) control (Herman \& Polivy, 1980, 1984; Polivy, 1976; Spencer \& Fremouw, 1979; Woody, Costanzo, Leifer, \& Conger, 1981). For dieters, of course, control of eating is tantamount to inhibition of eating. Such cognitive inhibition of intake seems especially prone to disruption (see Polivy \& Herman, 1983, for a review). Moreover, dieters seem to regulate their intake with respect to different limits or boundaries than those of nondieters (Herman \& Polivy, 1984). As long as their diets are not threatened or overwhelmed by excessive intake, dieters are motivated to eat (either by true hunger or by mealassociated external cues), but they eat a relatively small amount (compared with comparably deprived nondieters) and stop when they reach the idiosyncratic limit set by their diet quotas, which constrain permissible eating. Nondieters are more likely to eat until constrained by satiety, be it based on physiological or sensory inhibition (see Rolls, Rolls, \& Rowe, 1982, for a discussion of sensory-specific satiety). If the dieter's diet boundary becomes inoperative, either because it has been surpassed through overconsumption (in the laboratory a typical result of forced preloading) or because it has been forgotten under the sway of emotional agitation or intoxication, the dieter will eat more than the comparably preloaded or stressed nondieter and more than a dieter who has not been preloaded or stressed. This reversal of the normal response to preloading has been termed counterregulation, although the more recent (Herman \& Polivy, $1984)$ boundary analyses regard it as regulation by a different set of boundaries (Herman, Polivy, \& Esses, in press). Thus, under normal circumstances, dieters tend to eat less than nondieters, but following a variety of everyday events (e.g., stress in the form of anxiety, depression, or other dysphoric states; overeating induced by forced preloading in the laboratory, by eager hostesses at parties or social gatherings, by large restaurant portions, and by various mundane social pressures to indulge), dieters eat considerably more than nondieters. Indeed, in response to factors that suppress nondieters' eating. dieters often increase their intake (Herman \& Polivy, 1984). In most laboratory studies involving random samples of college coeds, about half the subjects exhibit the dieting pattern (eating restrictive amounts, becoming disinhibited, increasing intake) and half the subjects exhibit the nondieting pattern that is usually considered appropriate (i.e., eating more when deprived than when preloaded and more when calm and in control than when agitated). It is thus fair to ask, Which of these patterns is really normal? Physiologically, the behavior of the nondieters seems normal in that it is suitably responsive to natural or biological regulatory pressures; numerically, the dieters form a majority, which makes their behavior the norm. Thus, our understanding of normal eating depends on whether we refer to biological norms or societal norms. Certainly, according to current societal norms, the physiologically perverse dieting pattern is normal.

\section{Dieting and Eating Disorders: Continuum or Discontinuity?}

Dieting produces what might be called a disrupted eating pattern, but how does this pattern relate to the full-blown clinical eating disorders? Although certainly not all dieters have an eating disorder of diagnostic significance, a fair amount of speculation has related the increased incidence of anorexia nervosa to the intensified quest for a slim physique and to the dieting

\footnotetext{
' Simple obesity is considered a physical disorder by the DSM-III. which also points out that obesity is "not generally associated with any distinct psychological or behavioral syndrome" (American Psychiatric Association, 1980, p. 67). The defining characteristic of obesity is excess body weight such that the person is visibly fatter than average. Although such excess weight is generally thought to result from a higher than average intake of food or from a lower than average extent of exercise (or from a combination of the two), this is not invariably the case. Individual differences in the body weight set-point (Mrosovsky \& Powley. 1977) dictate that some people will be fatter than normal as a result of genetic/physiological factors rather than as a result of a voluntary positive energy balance. However, the majority of obese adults, particularly those who have undergone significant weight gain in adulthood, are probably overweight as a result of overeating. Although there is no single behavioral pattern or syndrome common to all obese people, a wide variety of personality traits are consensually ascribed to them. The obese are seen as neurotic and anxious (Moore, Stunkard, \& Srole, 1962) or as hyperemotional (Schachter, 1971), although more recent data refute this general portrait (Crisp \& McGuiness, 1975; Crisp, Queenan, Sittampaln, \& Harris, 1980). Bruch (1973) argued that a syndrome that affects as many people as obesity does is unlikely to be unicausal or characterizable in general terms; although this argument is not airtight logically, it probably does apply to obesity. In any case, Bruch focused on the emotional roots of overeating, which seems to serve a variety of stress-reducing and symbolically rewarding functions. Thus, stress-induced overeating has been described as a major contributor to obesity, although some confusion remains as to whether some people overeat because they are overstressed (or are less capable of coping with stress) or whether they overeat because stress directly causes them to eat.
} 
that such a quest seems to require (Garfinkel \& Garner, 1982; Garner, Garfinkel, \& Olmsted, 1983; Polivy, Garner, \& Garfinkel, 1981, 1986; Silverstein, 1986; Wooley, 1987; Wooley \& Wooley, 1982). Similarly, bulimia (Polivy \& Herman, 1985; Polivy, Herman, Olmsted, \& Jazwinski, 1984; Streigel-Moore, Silberstein, \& Rodin, 1986; Wardle \& Beinart, 1981; Wooley, 1987) and obesity (Orbach, 1978; Polivy \& Herman, 1983; Wooley \& Wooley, 1982) have been paradoxically linked to attempts to lose weight through dieting. It thus appears that dieting may be linked to all of the major eating disorders.

A link, even a causal link, does not mean that dieting is itself an eating disorder or is similar to an eating disorder. However, the causal connection is bolstered by accumulating evidence of similarity. All three eating disorders reflect a strong preoccupation with weight, and normal dieters are often equally preoccupied with their weight (Garner, Olmsted, \& Garfinkel, 1983; Garner, Olmsted, Polivy, \& Garfinkel, 1984). Similarly, a dissatisfaction with one's body or body image and a need or desire for perfection typifies both eating-disorder patients and normal dieters (Garner, Olmsted, \& Garfinkel, 1983; Garner et al., 1984). Finally, some apparent symptoms of anorexia nervosa and bulimia have been identified in normal dieters. Binge eating and self-induced vomiting have been reported in extreme dieters who do not show any other indications of psychopathology (Thompson \& Schwartz, 1982; Wardle, 1980; Wardle \& Beinart, 1981).

Given these observed similarities between normal dieters and patients suffering from recognized eating disorders, the question has repeatedly arisen as to whether dieting and eating disorders represent different points along a continuum of eating pathology (Button \& Whitehouse, 1981; Fries, 1977; Garner, Olmsted, \& Garfinkel, 1983; Garner et al., 1984; Nylander, 1971; Rodin et al., 1985; Streigel-Moore et al., 1986). Nylander (1971) first proposed such a "continuum hypothesis" of eating disorders when he surveyed female high school students in Sweden and found that the majority perceived themselves as overweight or fat and that a sizable percentage (nearly $10 \%$ ) reported three or more symptoms of anorexia nervosa in connection with weight-loss attempts. Nylander suggested that the starvation associated with dieting might trigger true eating disorders. Fries (1977) observed body image distortions and anorexic attitudes both in anorexia nervosa patients and in rigid dieters who otherwise failed to meet the diagnostic criteria for a true eating disorder, as did Garner and Garfinkel (1980) in their study of professional ballet dancers and models. Using various questionnaires, other investigators have found elevated scores indicative of some symptoms of eating disorders in normal college students (Button \& Whitehouse, 1981; Garner, Olmsted, \& Garfinkel, 1983; Garner et al., 1984; Wardle, 1980). Such evidence has often been regarded as demonstrating that eating disorders fall at the endpoint of a continuum of disordered eating, with chronic and intermittent dieters falling at intermediate points along the continuum (Button \& Whitehouse, 1981; Fries, 1977; Rodin et al., 1985; Streigel-Moore et al., 1986).

The notion of a continuum assumes that there are fundamental similarities between the true eating disorders (at one pole of the continuum) and the milder forms of the disorder that are arrayed along the continuum; the difference is basically a matter of degree, and normalcy (at the other pole of the continuum) represents the absence of the characteristics of pathology. This view is disputed by many clinical theorists who treat and discuss eating disorders: They argue that there are critical differences between the true syndromes and the milder syndromes seen in normal dieters. ${ }^{2}$ For example, Crisp (1965) argued that the anorexic patient and the normal dieter pursue dieting and thinness for very different reasons. The normal dieter is attempting to achieve positive goals (e.g., improved appearance, self-esteem, control) in the service of growth and development, whereas the anorexic patient uses dieting as an escape from the psychosocial demands of puberty and maturation. The anorexic patient becomes emaciated as a means of regressing to a prepubertal body shape and hormonal status in order to avoid growth and development to an adulthood with which she feels incapable of coping (Crisp, 1965). Bruch (1973), writing about anorexia nervosa and psychopathological obesity, also distinguished sharply between dieting and the more severe psychopathologies of eating. She maintained that true eating disorders involve distortions of body image and internal perceptions that are accompanied by an underlying sense of ineffectiveness. Weight control thus becomes the arena for the patient's struggles over autonomy and competence. Selvini-Palazzoli (1978) extended this position by postulating that the true disorder involves not only the perceptual and self-esteem deficits emphasized by Bruch but also a fundamental interpersonal distrust. These theorists thus posit a discontinuity between eating disorders and chronic dieting.

This question of continuity versus discontinuity was addressed explicitly in a recent study (Garner, Olmsted, \& Garfinkel, 1983; Garner, Olmsted, Polivy, \& Garfinkel, 1984) in which investigators developed a questionnaire designed to measure the psychological disturbances identified by Crisp, Bruch, and Selvini-Palazzoli as characteristic of patients with clinical eating disorders (Garner, Olmsted, \& Polivy, 1983a, 1983b). Like the earlier Eating Attitudes Test (Garner \& Garfinkel, 1979), the Eating Disorder Inventory (EDI) measures eatingrelated pathology as well as the less obvious traits that are theoretically related to eating disorders. The EDI subscales include Drive-for-Thinness, Bulimia, Body Dissatisfaction, Ineffectiveness, Perfectionism, Interpersonal Distrust, Lack of Interoceptive Awareness, and Maturity Fears. (See Garner, Olmsted, \& Polivy, 1983a, 1983b, for full descriptions of these subscales.) This questionnaire was validated on groups of anorexia nervosa and bulimia nervosa patients, and it was also administered to obese, formerly obese, and normal college women and men. Garner, Olmsted, and Garfinkel (1983) and Garner et al. (1984) used the EDI to compare normal college dieters, nondieters,

\footnotetext{
${ }^{2}$ The controversy about whether eating disorders lie on a continuum with normalcy (Meyer, 1957) or are qualitatively different (Kraepelin, 1913 ) is reminiscent of a similar debate regarding clinical depression and sad or depressed mood in normal individuals. Similarly, personality theorists have speculated for decades about whether personality as a whole may be placed on a continuum from normal to abnormal (e.g., Freud) or whether normal and abnormal personalities are discontinuous, differing in kind as well as in degree (e.g., Allport, 1950). If we fail to satisfactorily resolve the continuum controversy as it applies to eating in this article, at least we are in good company.
} 
ballet students, and patients with anorexia nervosa. The current discussion will focus on the Garner et al. (1984) article.

The college and ballet students were divided into two groups on the basis of their EDI Drive-for-Thinness subscale scores. The weight-preoccupied (WP) group in this study was defined more stringently than mere chronic dieters: Their level of concern about weight and dieting had to be comparable to that of the patient group, whereas the not weight-preoccupied (NWP) group consisted of students scoring below the mean for their respective samples. To confirm that high Drive-for-Thinness scores did indeed reflect weight preoccupation, $12 \mathrm{WP}$ and 12 NWP college women were interviewed by a clinical psychologist who was blind to their EDI scores but was experienced in diagnosing and treating eating disorders. Of the $12 \mathrm{WP}$ women interviewed, 3 were classified as having a current or prior eating disorder. Accordingly, after further screening, those college and ballet students who were deemed to have (or have had) a true eating disorder were eliminated from further consideration. Next, college and ballet student samples were combined because there were no significant differences between them (once the true eating-disordered subjects had been eliminated). This left three groups who were compared on the EDI subscales to determine whether weight preoccupation predicted psychopathology: NWP women, WP women, and anorexia nervosa patients.

These comparisons revealed that anorexic patients and WP women did not differ from each other and that both groups scored in a more pathological direction than did the NWP group on four subscales. On two subscales, all three groups differed from each other, and on one subscale the anorexic group scored more pathologically than did either other group. On most scales, the WP subjects scored in a more pathological direction than the NWP subjects, which seemed to imply a continuum. Cluster analysis of the EDI subscale scores, however, revealed that the WP group could be further subdivided into two groups. Cluster 1 comprised women with high scores on all subscales; these subscale scores were as high or higher than those of the anorexic patients. Cluster 2, which comprised two thirds of the WP women, displayed a more benign profile; these women scored high (as high as Cluster 1 or anorexic women) only on Drive-for-Thinness, Body Dissatisfaction, and Perfectionism subscales (the subscales more closely related to dieting efforts per se) and scored low (within the normal college student range) on all other subscales. The authors concluded that even when both types of WP subjects were considered together, the WP group displayed a degree of disjunction from the eating disordered group. ${ }^{3}$ The subclinical anorexia-nervosa pattern of pathology without severe weight loss that has been revealed in earlier studies (e.g., Button \& Whitehouse, 1981; Fries, 1977) appeared if only food, appearance, and weight-related concerns were examined. Thus, investigations of subclinical eating disorders that are based solely on measures of attitudes toward food, weight, and appearance are likely to lead to the conclusion that weight-preoccupied and eating-disordered women are indeed quite similar to each other. However, assessment of the other psychological and cognitive attributes of eating-disordered patients, including those postulated by Bruch (1973) and SelviniPalazzoli (1978), reveals noticeable and perhaps fundamental differences that might otherwise be overlooked. Psychologically, there appears to be some disparity between these groups.

Olmsted and Garner (1986) found a similar dichotomy in an investigation of college women who reported vomiting to control their weight. A cluster analysis revealed three groups: The first group had high EDI scores on all subscales and closely resembled anorexia nervosa or bulimia patients; the second group had high scores on only eating, weight, and body-shapeconcern items; and the third group had normal scores on all subscales. Analysis of the larger sample of college coeds (from which the vomiting women were drawn) also yielded two distinct groups of weight-preoccupied women along with a group that showed no eating or weight concerns.

In sum, the data suggest that there are two components to the pathology exhibited by patients with eating disorders (anorexia nervosa and bulimia in particular). One component-an intense concern with weight, appearance, body shape, and eating-may well be shared by normal dieters. A second component- the ego deficits and perceptual disturbances identified by Bruch and Selvini-Palazzoli-appears to be confined to a more restricted segment of the population. Although it is not clear whether the college and ballet students with this more pathological profile actually had an undiagnosed eating disorder or a subthreshold eating disorder (see Fairburn \& Garner, 1986), they did seem to differ from those women who displayed only the first component of eating pathology. Without longitudinal data, we cannot determine whether a continuum or progression exists in the sense that people exhibiting the first (eating-related) component will eventually develop the second (deeper) component. On the basis of the available cross-sectional data, however, it seems that real eating disorders share some characteristics with dieting but qualitatively differ from stringent dieting on the EDI subscales of Ineffectiveness, Lack of Interoceptive Awareness, Interpersonal Distrust and, to a lesser degree, Maturity Fears.

Eating-disordered patients and weight-preoccupied dieters do share some pathological behaviors and attitudes. The drive for thinness and its associated intense concern with dieting, weight, and appearance; the bulimia (binge eating with or without purging); and the serious dissatisfaction with one's body that characterize eating disorders appear to a greater or lesser extent among many normal dieters. Although dieting may not represent a nonpathological stage on a continuum from normalcy to eating disorders (because there does not appear to be such a simple, unitary, continuous dimension), it clearly can be associated with some of the pathology accepted as a core feature of the eating disorders (Fairburn \& Garner, 1986).

\section{Are Eating Disorders Disorders of Eating?}

If normal dieters exhibit weight and body-shape concerns indistinguishable from those of patients with eating disorders, the

\footnotetext{
${ }^{3}$ Research with the EDI and other psychometric measures has indicated that anorexia nervosa and bulimia patients resemble each other in profile features and overall pathology scores (Fairburn \& Cooper, 1984; Garner, Garfinkel, \& O'Shaughnessy, 1985; Garner, Olmsted, \& Garfinkel, 1985; Garner, Olmsted, \& Polivy, 1983a, 1983b). Obese patients have shown considerably more diversity on these psychometric measures (Garner, Olmsted, \& Polivy, 1983a, 1983b).
} 
distinctive quality of an eating disorder must lie elsewhere, perhaps in eating behavior per se. Some psychological attributes that are unrelated to eating, weight, and body-shape concerns (i.e., feelings of ineffectiveness and interpersonal distrust, maturity fears, and a lack of interoceptive awareness) seem to distinguish eating-disorder patients from chronic dieters. But because the disorders are called eating disorders, one must assume that there is something associated with eating that is disordered and that discriminates eating-disorder patients from those who are merely weight-concerned or preoccupied.

It appears that anorexia nervosa, bulimia nervosa, atypical eating disorders, and obesity all involve disordered eating. Anorexics eat too little, the obese eat too much, and bulimics eat too much at one time (and too little at others). The term dietary chaos (Palmer, 1979) was proposed to describe the disorder of bulimia (or bulimia nervosa as it is termed by the DSM-III$R$ ), and implies that the bulimic's eating is chaotic or out-ofcontrol. The bulimic patient's eating is perhaps the most chaotic, but even the obese are seen as being driven or lured to eat by a bewildering variety of forces beyond their control, both inside and outside their bodies. Schachter (1971; Schachter \& Rodin, 1974) described the obese as "stimulus-bound" and argued that their eating is determined largely by external, environmental influences such as the sight or smell of food. Anorexics, on the other hand, are seen as unable to eat sufficient amounts because their rigid diets control them (Bruch, 1973). Thus, eating disorders do seem to be disorders of eating in that eating is out-of-control, chaotic, and unregulated.

However, it is possible to interpret the eating behavior of all of these eating-disordered individuals as reordered rather than disordered. That is, their eating behavior may reflect a different mode of regulation rather than the absence of regulation or control. The boundary model of eating behavior (Herman \& Polivy, 1984) proposes that eating, in the undisturbed organism, is triggered and terminated by interoceptively detected signals associated with the phenomenal states of hunger and satiety. But this model goes beyond the foregoing truism to suggest that there is an intermediate condition between hunger and satiety in which the organism is indifferent and eating is neither negatively reinforced (as when the organism is hungry) nor punished (as when the organism is sated). Within this zone of indifference, eating may be under the primary control of social, environmental, and cognitive factors; these factors are naturally less effective in the control of eating when the organism is hungry or sated (in which case, physiological demands take precedence).

Dieters differ from undisturbed people in that they are characterized by a third boundary (the diet boundary) that is deliberately interposed between the hunger and satiety boundaries. The diet boundary represents the dieter's attempt to inhibit eating before normal satiety processes are activated; this attempt is the essence of a diet. Presumably, this inhibition of eating will produce (and maintain) weight loss. However, the imposition of a diet boundary ultimately has unfortunate consequences for regulatory well-being. As we discussed previously, research on normal dieters has indicated that when the diet boundary is breached, dieters display eating patterns similar to the dietary chaos of bulimic patients (Herman \& Polivy, 1984; Polivy et al., 1984). More detailed analysis (Herman et al., in press) has indicated that the dieter's disinhibited eating after a forced pre- load is not truly counterregulatory or chaotic but rather is regulated by a different inhibitory boundary. After a small preload (or none at all), the dieter eats very little ad-lib food, presumably because the diet boundary is still controlling consumption. After a larger preload, the dieter eats a great deal because the diet boundary is no longer relevant (having been surpassed); the next relevant boundary is provided by the sensation of physiological satiety, and such satiety may not occur until a lot of additional food has been consumed. After an extremely large preload, however, the dieter eats only a small amount ad lib because only a small amount of additional food is needed to incur satiety sensations. The nondieter, by contrast, eats a great deal after a small preload because a great deal of food may be consumed before satiety sets in. After a large preload, relatively less food may be consumed before satiety inhibits eating. Interestingly, after identical large preloads, the dieter tends to eat quite a bit more than the nondieter. Because both types of individual should then be under the control of the physiological satiety boundary, they should eat the same amount. Dieters may eat more because, for chronic dieters, the satiety boundary is shifted further away from the hunger boundary; in effect, the chronic dieter may lose the ability to detect the subtle precursors of satiety (i.e., anticipatory satiety signals), with the result that it takes a substantially greater amount of food or stomach distention to inhibit eating in the dieter who is temporarily forced to fall back on the sporadically used satiety boundary as a guide to terminating consumption. ${ }^{4}$

The eating behavior of patients with eating disorders may also be explained, or at least described, by this simple boundary model. Thus, anorexic patients have a very stringent diet boundary, which is often set close to the hunger boundary. The small amounts that anorexics eat are thus severely limited by this cognitive diet boundary that restricting anorexics seldom, if ever, transgress. Bulimics also tend to have a very stringent diet boundary that, if it were consistently honored, would make them indistinguishable from restricting anorexics. (Both anorexics and bulimics appear to have a lowered hunger boundary that corresponds to their ability to tolerate greater degrees of food deprivation than normal. This shifted hunger boundary makes it easier to explain their ability to keep their consumption below the level dictated by the diet boundary because adherence to these restrictive quotas does not create the same intensity of hunger that it might create in ordinary individuals.)

Bulimics, of course, do not always succeed in honoring the diet boundary. Binges arise from either the (perceived) transgression of the diet boundary (see Polivy, 1976; Spencer \& Fremouw, 1979; and Woody et al., 1981 for experimental demonstrations of disinhibition by perceived high calorie preloads in normal dieters) or, perhaps more frequently, from the functional elimination of the diet boundary by emotional agitation. Of course, the more seriously the individual is concerned with restricting her intake, the lower she sets her diet boundary and the more likely it is that her boundary will be transgressed by a

\footnotetext{
${ }^{4}$ It has been argued (Rodin, 1981) that almost everyone displays some insensitivity or unresponsiveness to hunger and satiety cues. Of course, many of Rodin's individuals may have been dieters; but even nondieters, as we have seen, should display more externality than internality when in the zone of indifference.
} 
particular indulgence resulting in disinhibition. Such serious dieters also seem prone to emotional agitation (see Polivy, Herman, \& Warsh. 1978, for an analysis of hyperemotionality in dieters), which again increases the odds in favor of disinhibited eating episodes. Like normal dieters, disinhibited bulimics eat much more than they would if the diet boundary was still exerting its customary inhibition. Clinical binge eaters, however, differ from normal dieters in that they tend to eat well beyond the satiety level that eventually stops dieters. As we noted previously, disinhibited dieters tend to have a shifted satiety boundary, which accounts for their elevated consumption (compared with that of nondieters) after a large preload. However, the binge eater tends to surpass even this shifted satiety boundary and continues to eat voraciously either until there is no food left or until the limits of physical capacity (i.e., stomach distention) are reached (Polivy et al., 1984).

To the extent that obese individuals are dieters or are bulimic, the foregoing analysis applies to them as well. They appear to regulate their eating within wider boundaries; that is, they can tolerate more food deprivation without being impelled by hunger, and they can eat considerably more food at a sitting without incurring the discomforts of satiety. Most of the time, the obese occupy the zone of indifference in which they are especially susceptible to the influence of external, environmental cues to eat (or, occasionally, to stop eating). Of course, being afflicted with such wide boundaries (especially a delayed satiety boundary) is sufficient cause to consider a self-imposed diet boundary. Alternatively, being overweight might itself be sufficient justification for a self-imposed diet boundary (Herman \& Polivy, 1980), even if hunger and satiety processes are initially normal. Strict adherence to a diet boundary might then (further) widen the zone between hunger and satiety as the obese individual converts his regulatory system from one based on hunger or satiety to one based on diet considerations (irrespective of hunger or satiety). The atrophy of hunger and satiety signals, or the atrophy of the ability to respond promptly to them, ensues when the (obese) dieter no longer experiences the conditioned, anticipatory hunger or satiety cues that arise from normal avoidance of these aversive states. Eventually, hunger is perceived only when it becomes intense, and the sensation of satiety requires relatively enormous stomach loads.

Application of the boundary model to the eating behavior of individuals with eating disorders, then, suggests that their eating may not be chaotic; rather, it may well be regulated by regulatory boundaries that do not apply to normal eaters. The eating displayed by those with eating disorders may well be described as pathological, both physically and psychologically, but may not necessarily be described as disordered.

The pathologies of eating that are observed in eating-disordered patients are, to a great extent, apparent in normal dieters. The diet boundary, which is a central feature of the normal dieter, promotes caloric restriction but not to the same extent as that operant in anorexics. When the diet boundary is breached, dieters tend to overeat substantially but not to the dramatic extent evident in bulimics. ${ }^{5}$ Thus, although pathological eating is characteristic of eating-disordered patients, it does not really distinguish them from normal dieters except, perhaps, in quantitative terms. The eating-disordered individual may engage in more strenuous restriction and more prodigious binges, but the dividing line is not at all well-marked, and it is difficult to distinguish between patient and nonpatient groups.

What distinguishes an eating disorder, then, is not the disorder of eating. It is obviously true that patients who display eating disorders exhibit pathological eating patterns. Likewise, their obsessive concerns with weight and appearance are not signs of psychological well-being. But these particular pathological elements, shared as they are with normal dieters, are societally normative and even acceptable: In some circles, they are regarded as commendable! (See Branch and Eurman's, 1980, account of envy among anorexics' family and friends.) It is only when these elements are combined further with the personality defects of low self-esteem, fears about interpersonal relationships and the responsibilities of maturity, and a loss of touch with internal signals of all sorts, that a societal diagnosis of abnormality is rendered.

Because these further personality defects are also fundamental to a number of other mental disorders, such as depression and hysteria, we are tempted to regard patients with eating disorders as vulnerable individuals whose vulnerability is played out on the broad and heavily populated field of weight restriction and obsessive concern with appearance (see also Garfinkel \& Garner, 1982; Garner, 1986; Garner \& Bemis, 1985). Thus, one might argue that the current upsurge in the number of patients with eating disorders reflects the prevalence of an eating/ weight/appearance pathology in society that preys on those with weak and susceptible personality formations. Such individuals are likely to develop some sort of mental disorder under stress; society's eating/weight pathology simply channels the pathology into an eating disorder (rather than into hysteria or conversion disorder, outcomes that were popular a century ago but that are seen only rarely today). As long as this eating/ weight pathology is normal in Western saciety, we can expect to see large numbers of eating-disordered patients.

\section{Treatment of Normal Eating}

The reason for the apparent paradox in the title of this article should by now be evident. When societal norms evolve such that pathological behavior is not only countenanced but encouraged, health care workers must learn to diagnose and treat normal behaviors. We argue that this is currently the case for eating behavior. Chronic dieting is now the norm, but it requires behaviors and attitudes that are seif-destructive and pathological.

Normal eating may be treated with many of the same procedures used to treat anorexia, bulimia, and obesity because at least part of the goal is the same: Eating must be returned to physiological normalcy, and attitudes regarding weight and appearance must be modified. Cognitive and behavioral therapies have been proposed and have been applied widely to eating disorder patients (Fairburn, 1985; Garner \& Bemis, 1985; Garner, Rockert, Olmsted, Johnson, \& Coscina, 1985; Mahoney \& Ma-

\footnotetext{
${ }^{5}$ Because the obese are so heterogeneous, it is correspondingly difficult to describe their characteristic eating pattern. Clinical data suggest that many obese patients do binge in a manner similar to that of bulimics or dieters (Gormally, Black, Daston, \& Rardin, 1982; Loro \& Orleans, 1982).
} 
honey, 1976, Marlatt \& Gordon, 1986), with success rates that have varied according to how success is defined (Garner, Fairburn, \& Davis, in press). Although similar strategies seem warranted for the treatment of normal dieting, we suggest a greater focus on the return to physiologically normal eating, with the elimination of dietary restraints that are codified in weight-reduction diets (Polivy \& Herman, 1983).

Many weight-related concerns are implicitly or explicitly focused by dietmongers on the threats posed by uninhibited eating. The dieter fears allowing herself to eat naturally and expects that the result will be uncontrollable binging and weight gain. In fact, the sorts of dishinhibited eating that the dieter fears actually arise from dieting itself (Polivy \& Herman, 1985). Truly uninhibited eating, which is responsive to active (and even anticipatory) satiety cues, does not lead to overeating and certainly does not lead to binging (Ciliska, 1986); indeed, dieters often lose weight by abandoning their diets (Polivy \& Herman, 1983). The reversion to physiologically (rather than cognitively) controlled eating will also have salutary effects on attitudes; obsessions with dieting are likely to dissipate when it becomes clear that normal eating is not a significant threat to one's well-being. Most exdieters appreciate their liberation from obsessive diet-consciousness (Ciliska, 1986).

A return to physiological normalcy, however, may not appear (to many dieters) to be an easy achievement. Physiologically normal eating involves eating in response to the physiological correlates of hunger, accurately perceived. But these pathological events are subject to conditioning, so if meals are reliably paired with certain stimuli, including the passage of time, hunger will be perceived when such cues are presented, regardless of the subject's actual state of nutritional deficit (Weingarten, 1985). These cues, however, are not likely to elicit uncontrolled overindulgence, even if they are technically unrelated to the subject's true caloric needs. Satiety cues are also conditionable (Stunkard, 1975). We define normal eating simply as eating that occurs in response to hunger cues and stops in response to satiety cues. To learn (or relearn) to respond to such cues, one must perceive them with accuracy.

Perhaps the most insidious effect of dieting is its interference with the perception of normal hunger and satiety signals. To be successful, a dieter must overcome such signals; that is, she must learn to not eat when hungry and to terminate eating in response to arbitrary signals that occur well before satiety. Chronic disuse of normal hunger and satiety signals for the regulation of eating not only produces the sort of distorted regulation of eating that we have seen in our normal dieters but also gradually undermines the dieter's capacity to perceive hunger and satiety cues and to use them efficiently. (This may be a subclinical variant on the lack of interoceptive awareness that is characteristic of eating-disordered patients.) As we have demonstrated with our boundary model, dieters lose touch with hunger and satiety in that (a) it takes more deprivation to induce an awareness of hunger, and (b) it takes more indulgence to induce an awareness of satiety. Either these signals or the dieter's capacity to recognize these signals have atrophied. Clearly, the return to normal eating requires the exdieter's reacquaintance with hunger and satiety signals. This process might be facilitated by explicit perceptual exercises based on systematic reconditioning of hunger and satiety cues and should occur, for example, if eating is temporally programmed. Reacquaintance with hunger and satiety signals will, in turn, permit their use as guides to ingestion, without the fear of loss-of-control.

The non-eating pathologies present in normal eaters and dieters must also receive some attention. The belief that it is important to achieve and maintain a slim physique to be worthwhile or to lead a satisfying life requires modification. The fallacy underlying this belief - that one's life would improve significantly if one could only lose weight-demands an explicit analysis and critique. Similarly, because obesity does not respond well to diet therapies, it is important to correct the mistaken belief that substantial weight loss is possible for all but a small minority of women. Finally, we must address the implicit rejection of onself that is involved in the decision to diet (i.e., to seek to become someone other than who one is). Who, exactly, is the dieter trying to become? What is unacceptable about the person she or he currently is? Teaching people to like and accept themselves will probably be the most difficult aspect of treating normal eating. ${ }^{6}$

For this therapy to succeed, it must proceed on two levels. Therapy for mental disorders usually focuses on the individual or on the individual plus the immediate social and familial milieu. But because the pathology of dieting is socially normative and is now synonomous with normal eating, society itself must be treated along with the individual victims. Until society abandons its obsession with thinness and dieting, treatment at the individual level will be difficult because the patient's environment will continue to encourage and to reward pathology (e.g., Branch \& Eurman, 1980; Wooley, 1987). When society recognizes and agrees to treat its eating disorder, as it is now gradually treating its smoking disorder, society's members will be more amenable to individual therapy as well.

\section{Research Implications}

Our examination of the pathology of normal eating and dieting rests on some assumptions that need further testing; our analysis also raises many further questions. For example, although dieting seems to precede binge eating (Polivy \& Herman, 1985), is dieting the primary cause of the observed pathology associated with it? Or do pathology-prone people choose to diet?

Consider the association between dieting and low self-esteem. Extremely low self-esteem is a discriminating characteristic of eating-disorder patients. Some data have likewise suggested that chronic dieters have lower self-esteem than do nondieters (Heatherton, Polivy, Pliner, \& Herman, 1986; Wooley \& Wooley, 1984). Is it low self-esteem that prompts the individual to change (through dieting)? Or does dieting have detrimental effects on self-esteem (because of the dieter's failure to lose

\footnotetext{
${ }^{6}$ Obviously, not all dieters are distressed by their dieting, and some report improvements in self-esteem along with weight loss (e.g., Wing, Epstein, Marcus, \& Kupfer, 1984). Some of these satisfied dieters may engage in misattribution and may mistakenly credit all positive outcomes to their dieting and all negative outcomes to their dieting failures. In any case, satisfied dieters are in the minority (e.g., Wooley, 1987). Our treatment recommendations are directed (at least initially) toward the dissatisfied majority.
} 
weight, to stick with the diet, or to achieve the benefits of a new self)? The causal primacy of dieting and its correlated pathologies must be established.

The question of whether a continuity exists between normal eating, normal dieting, and eating disorders offers wide latitude for investigation. Which dieters are at risk for moving along the continuum or for changing categories? What do the subclinical pathologies represent? Are subthreshold eating disorders precursors of anorexia or bulimia, or are they long-standing conditions that the individual may maintain without further pathological progression? Do the seriously weight-preoccupied dieters move toward a subthreshold disorder (or even a full-blown disorder), or are these positions chronic? Do weight-preoccupied dieters eventually develop the sort of non-eating-related pathologies that characterize eating-disordered patients, or do they remain concerned only with weight, eating, and body shape? How does chronic weight concern affect other aspects of personality and behavior? The general personality pathology identified in eating-disordered patients must be documented more completely: This is a prerequisite for the development of effective therapies. Finally, we need a coherent understanding of the obesities. How can they be classified? Which are pathological and which are not? Where do they fit into the discussion of eating and personality pathologies?

The boundary model of eating may be used to describe the behavior of eating-disordered patients and the apparently disordered behavior of dieters. But the explanation of eating and its pathologies requires experimental support. Whether eating is actually regulated in the manner suggested by the boundary model is an empirical question. The parameters of eating in all segments of the population require more detailed attention; this is particularly true for the eating disorders. Some experimental investigations of eating in bulimic patients have begun (B. J. Rolls, personal communication, October 22, 1985), but many more are needed. Such research is especially difficult because the demand for scientific rigor often conflicts with ethical concerns over patients' distress. Rather than avoiding the enterprise, we must negotiate compromises that jeopardize neither the value of the data nor the rights and feelings of the patients. The use of consenting hospitalized patients and less intrusive measures and techniques can yield useful data, even when ongoing therapeutic regimes are merely monitored (e.g., Stordy, Marks, Kalucy, \& Crisp, 1977).

Finally, the treatment we have proposed to provide an alternative to calorically restrictive dieting is only beginning to be tested (Ciliska, 1986; Polivy \& Herman, 1983). By eliminating dieting and focusing on hunger and satiety as regulators of food intake, do we create more stable eating patterns? Are problematic attitudes and concerns about food, weight, and shape alleviated by simply changing eating behavior? What are the benefits of a return to normal, physiologically regulated eating? If we focus on creating new attitudes, will eating normalize itself without additional intervention? Can we treat the personality defects that are associated with eating disorders? Is it necessary (or feasible) to treat society as well as the individual? Will a successful societal reeducation program eventually reduce the need for individual therapy?

Obviously, there are a multitude of questions awaiting answers, and some of these answers are starting to emerge. We hope that our paradoxical focus on normal pathology will foster more research and will help to redefine the issues. Our focus on the pathology of the norm is intended to draw attention to the dangers inherent in societally sanctioned dieting and to emphasize the contribution of this pathological climate to the development of recognized eating disorders. Dieting may be less devastating than these recognized disorders, but we condone it only at our peril.

\section{References}

Allport, G. W. (1950). The nature of personality: Selected papers. Cambridge, MA: Addison-Wesley.

American Psychiatric Association. (1980). Diagnostic and statistical manual of mental disorders. Washington, DC: Author.

American Psychiatric Association. (1987). Diagnostic and statistical manual of mental disorders (3rd ed., rev.). Washington, DC: American Psychiatric Press.

Branch, C. H. H., \& Eurman, L. J. (1980). Social attitudes toward patients with anorexia nervosa. American Journal of Psychiatry, 137 , 631-632.

Bruch, H. (1973). Eating disorders. New York: Basic Books.

Button, E. J., \& Whitehouse, A. (1981). Subclinical anorexia nervosa. Psychological Medicine, 11, 509-516.

Ciliska, D. (1986). The effects of an intervention program on the selfesteem of obese women. Unpublished doctoral dissertation [research in progress], University of Toronto.

Crisp, A. H. (1965). Some aspects of the evolution, presentation and follow-up of anorexia nervosa. Proceedings of the Royal Society of Medicine, 58, 814-820.

Crisp, A. H., \& McGuiness, B. (1975). Jolly fat: Relation between obesity and psychoneurosis in the general population. British Medical Journal, 1, 7-9.

Crisp, A. H., Queenan, M., Sittampaln, Y., \& Harris, G. (1980). 'Jolly fat' revisited. Journal of Psychosomatic Research, 24, 233-241.

DeJong, W., \& Kleck, R. E. (1986). The social psychological effects of overweight. In C. P. Herman, M. P. Zanna, \& E. T. Higgins (Eds.), Physical appearance, stigma, and social behavior: The Third Ontario Symposium in Personality and Social Psychology (pp. 65-88). Hillsdale, NJ: Erlbaum.

Fairburn, C. G. (1985). The management of bulimia. Journal of Psychiatric Research, 19, 465-472.

Fairburn, C. G., \& Cooper, P. J. (1984). Binging eating, self-induced vomiting and laxative abuse: A community study. Psychological Medicine, 14, 401-410.

Fairburn, C. G., \& Garner, D. M. (1986). The diagnosis of bulimia nervosa. International Journal of Eating Disorders, 5, 403-419.

Fries, H. (1977). Studies on secondary amenorrhea, anorectic behavior and body image perception: Importance for the early recognition of anorexia nervosa. In R. Vigersky (Ed.), Anorexia nervosa (pp. 163176). New York: Raven.

Garfinkel, P. E., \& Garner, D. M. (1982). Anorexia nervosa: A multidimensional perspective. New York: Brunner/Mazel.

Garner, D. M. (1986). Cognitive therapy for bulimia nervosa. In S. C. Feinstein (Ed.), Adolescent psychiatry: Developmental and clinical studies (Vol. 13, pp. 358-390). Chicago: University of Chicago Press.

Garner, D. M., \& Bemis, K. M. (1985). A cognitive-behavioral approach to anorexia nervosa. Cognitive Therapy and Research. 6. 123-150.

Garner, D. M., Fairburn, C., \& Davis, R. B. (in press). Cognitive-behavioral treatment of bulimia nervosa: A critical appraisal. Behavior Modification.

Garner, D. M., \& Garfinkel, P. E. (1979). The Eating Attitudes Test: An 
index of the symptoms of anorexia nervosa. Psychological Medicine, 9. 273-279.

Garner, D. M., \& Garfinkel, P. E. (1980). Sociocultural factors in the development of anorexia nervosa. Psychological Medicine, 10, 647656.

Garner, D. M., Garfinkel, P. E., \& Olmsted, M. P. (1983). An overview of sociocultural factors in the development of anorexia nervosa. In P. L. Darby, P. E. Garfinkel, D. M. Garner, \& D. V. Coscina (Eds.), Anorexia nervosa: Recent developments (pp. 65-82). New York: Alan R. Liss.

Garner, D. M., Garfinkel, P. E., \& O'Shaughnessy, M. (1985). Validity of the distinction between bulimia with and without anorexia nervosa. American Journal of Psychiatry, 142, 581-587.

Garner, D. M., Garfinkel, P. E., Schwartz, D., \& Thompson, M. (1980). Cultural expectations of thinness in women. Psychological Reports, 47, 483-491.

Garner, D. M., Olmsted, M. P., \& Garfinkel, P. E. (1983). Does anorexia nervosa exist on a continuum? Subgroups of weight-preoccupied women and their relationship to anorexia nervosa. International Journal of Eating Disorders, 2, 11-20.

Garner, D. M., Olmsted, M. P., \& Garfinkel, P. E. (1985). Similarities among bulimic groups selected by weight and weight history. Journal of Psychiatric Research, 19, 129-134.

Garner, D. M., Olmsted, M. P., \& Polivy, J. (1983a). Development and validation of a multi-dimensional eating disorder inventory for anorexia nervosa and bulimia. International Journal of Eating Disorders, 2, 15-34.

Garner, D. M., Olmsted, M. P., \& Polivy, J. (1983b). The Eating Disorder Inventory: A measure of cognitive behavioral dimensions of anorexia nervosa and bulimia. In P. L. Darby, P. Garfinkel, D. M. Garner, \& D. V. Coscina (Eds.), Anorexia nervosa: Recent developments (pp. 173-184). New York: Alan R. Liss.

Garner, D. M., Olmsted, M. P., Polivy, J., \& Garfinkel, P. E. (1984). Comparison between weight-preoccupied women and anorexia nervosa. Psychosomatic Medicine, 46, 255-266.

Garner, D. M., Rockert, W., Olmsted, M. P., Johnson, C., \& Coscina, D. V. (1985). Psychoeducational principles in the treatment of bulimia and anorexia nervosa. In D. M. Garner \& P. E. Garfinkel (Eds.), Handbook of psychotherapy for anorexia nervosa and bulimia (pp. 513-572). New York: Guilford Press.

Gormally, J., Black, S., Daston, S., \& Rardin, D. (1982). Assessment of binge eating severity among obese persons. Addictive Behaviors, 7 . 47-55.

Heatherton, T., Polivy, J., Pliner, P., \& Herman, C. P. (1986). Self-esteem. body weight and dieting status. Unpublished manuscript.

Herman, C. P., \& Polivy, J. (1980). Restrained eating. In A. J. Stunkard (Ed.), Obesity (pp. 208-225). Philadelphia, PA: Saunders.

Herman, C. P., \& Polivy, J. (1984). A boundary model for the regulation of eating. In A. J. Stunkard \& E. Stellar (Eds.), Eating and its disorders (pp. 141-156). New York: Raven.

Herman, C. P., Polivy, J., \& Esses, V. M. (in press). The illusion of counterregulation. Appetite.

Jacobovits, C., Halstead, P. Kelley, L., Roe, D. A., \& Young, C. M. (1977). Eating habits and nutrient intakes of college women over a thirty year period. Journal of the American Dietetic Association, 71, 405-411.

Kraepelin, E. (1913). Manic-depressive insanity and paranoia. In R. M. Barclay (Ed. and Trans.), Textbook of psychiatry (pp. 135142). Edinburgh, Scotland: Livingstone.

Loro, A. D., \& Orleans, C. S. (1982). Binge eating in obesity: Preliminary findings and guidelines for behavioral analysis and treatment. Addictive Behaviors, 6, 155-166.

Mahoney, M. J., \& Mahoney, K. (1976). Permanent weight control. New York: Norton.
Marlatt, G. A., \& Gordon, J. R. (1986). Relapse prevention: Maintenance strategies for addictive behavior change. New York: Guilford Press.

Meyer, A. (1957). Psychobiology: A science of man. Springfield, IL: Charles C Thomas.

Moore, M. E., Stunkard, A. S., \& Srole, L. (1962). Obesity, social class, and mental illness. Journal of the American Medical Association. 181 , 962-966.

Mrosovsky, N., \& Powley, T. L. (1977). Set points for body weight and fat. Behavioral Biology, 20, 205-223.

Nylander, J. (1971). The feeling of being fat and dieting in a school population: Epidemiologic interview investigation. Acta Sociomedica Scandinavica, 3, 17-26.

Olmsted, M. P., \& Garner, D. M. (1986). The significance of self-induced vomiting as a weight control method among non-clinical samples. International Journal of Eating Disorders, 5, 683-700.

Orbach, S. (1978). Fat is a feminist issue. London: Paddington Press.

Palmer, R. L. (1979). The dietary chaos syndrome: A useful new term? British Journal of Medical Psychology, 52, 187-190.

Polivy, J. (1976). Perception of calories and regulation of intake in restrained and unrestrained subjects. Addictive Behaviors, 1, 237-243.

Polivy, J., Garner, D. M., \& Garfinkel, P. E. (1981, May). Thinness and social behavior. Paper presented at the Ontario Symposium on Personality and Social Psychology, Toronto, Ontario, Canada.

Polivy, J., Garner, D. M., \& Garfinkel, P. E. (1986). Causes and consequences of the current preference for thin female physiques. In C. P. Herman, M. P. Zanna, \& E. T. Higgins (Eds.), Physical appearance, stigma, and social behavior: The Third Ontario Symposium in Personality and Social Psychology (pp. 89-112). Hillsdale, NJ: Erlbaum.

Polivy, J., \& Herman, C. P. (1983). Breaking the diet habit. New York: Basic Books.

Polivy, J., \& Herman, C. P. (1985). Dieting and binging. American Psychologist. 40, 193-210.

Polivy, J., Herman, C. P., Olmsted, M. P., \& Jazwinski, C. M. (1984). Restraint and binge eating. In C. Hawkins, W. Fremouw, \& P. Clement (Eds.), The binge-purge syndrome (pp. 104-121). New York: Springer.

Polivy, J., Herman, C. P., \& Warsh, S. (1978). Internal and external components of emotionality in restrained and unrestrained eaters. Journal of Abnormal Psychology, 87, 497-504.

Rodin, J. (1981). Current status of the internal-external hypothesis for obesity: What went wrong? American Psychologist, 36, 361-372.

Rodin, J., Silberstein, L. R., \& Streigel-Moore, R. H. (1985). Women and weight: A normative discontent. In T. B. Sonderegger (Ed.), Nebraska Symposium on Motivation: Vol. 32. Psychology and gender (pp. 267-307). Lincoln: University of Nebraska Press.

Rolls, B. J., Rolls, E. T., \& Rowe, E. A. (1982). The influence of variety on human food selection and intake. In L. M. Barker (Ed.), The psychobiology of human food selection (pp. 101-122). Westport, CT: AVI.

Schachter, S. (1971). Some extraordinary facts about obese humans and rats. American Psychologist, 26, 129-144.

Schachter, S., \& Rodin, J. (1974). Obese humans and rats: Potomac, MD: Erlbaum.

Selvini-Palazzoli, M. (1978). Self-starvation: From individuation to family therapy in the treatment of anorexia nervosa. New York: Aronson.

Silverstein, B. (1986). The role of the mass media in promoting a thin standard of bodily attractiveness for women. Sex Roles, 14, 519-532.

Silverstein, B., Perdue, L., Peterson, B., Vogel, L., Fantini, D. (1986). Possible causes of the thin standard of bodily attractiveness for women. International Journal of Eating Disorders, 5, 907-916.

Spencer, J. A., \& Fremouw, W. J. (1979). Binge eating as a function of 
restraint and weight classification. Journal of Abnormal Psychology, 88, 262-267.

Stordy, B. J., Marks, V., Kalucy, R. S., \& Crisp, A. H. (1977). Weight gain, thermic effect of glucose and resting metabolic rate during recovery from anorexia nervosa. American Journal of Clinical Nutrition, 30, 138-146.

Streigel-Moore, R. H., Silberstein, L. R., \& Rodin, J. (1986). Toward an understanding of risk factors for bulimia. American Psychologist. 4l, 246-263.

Stunkard, A. S. (1975). Satiety is a conditioned reflex. Psychosomatic Medicine, 37, 383-387.

Thompson, M. G., \& Schwartz, D. M. (1982). Life adjustment of women with anorexia nervosa and anorexic-like behavior. International Journal of Eating Disorders, 1, 47-60.

Wardle, J. (1980). Dietary restraint and binge eating. Behavioral Analysis and Modification, 4, 201-209.

Wardle, J., \& Beinart, H. (198I). Binge eating: A theoretical review. British Journal of Clinical Psychology, 20, 97-109.

Weingarten, H. (1985). Stimulus control of eating: Implications for a 2factor theory of hunger. Appetite, 6, 387-401.
Wing, R. R., Epstein, L. H., Marcus, M. D., \& Kupfer, D. J. (1984) Mood changes in behavioral weight loss programs. Journal of Psychosomatic Research, 28, 189-196.

Woody, E. Z., Costanzo, P. R., Leifer, H., \& Conger. J. (1981). The effects of taste and caloric perceptions on the eating behavior of restrained and unrestrained subjects. Cognitive Research and Therapy. 5, 381-390.

Wooley, S. C. (1987). Psychological and social aspects of ohesity. In A. E. Bender \& L. J. Brookes (Eds.), Body weight control: The physiology, clinical treatment and prevention of obesity (pp. 177-185). New York: Livingstone.

Wooley, S. C., \& Wooley, O. W. (1982). The Beverly Hills eating disorder: The mass marketing of anorexia nervosa. International Journal of Eating Disorders, 2, 57-69.

Wooley, S. C., \& Wooley, O. W. (1984, February). Feeling fat in a thin society. Glamour, pp. 198-201, 251-252.

Received March 4, 1987

Revision received March 31, 1987

Accepted April 20, 1987

\section{APA Convention "Call for Programs"}

The APA "Call for Programs" for the 1988 annual convention will appear in the October issue of the APA Monitor. The 1988 convention will be in Atlanta, Georgia, from August 12 to August 16. Deadline for submission of programs and papers is December 21, 1987. This early deadline is required because the 1988 convention is earlier in August than in the past. Additional copies of the "Call" will be available from the APA Convention Office in October. 